American J. of Engineering and Applied Sciences 1(3): 188-191, 2008

ISSN 1941-7020

(C) 2008 Science Publications

\title{
Identification of Shear Band using Elastic Shear Wave Propagation
}

\author{
${ }^{1}$ T. Nachiengtai, ${ }^{1} \mathrm{~W}$. Chim-Oye, ${ }^{2} \mathrm{~S}$. Teachavorasinskun and ${ }^{3} \mathrm{~W}$. Sa-Ngiamvibool \\ ${ }^{1}$ Faculty of Engineering, Thammasat University, Thailand \\ ${ }^{2}$ Faculty of Engineering, Chulalongkorn University, Thailand \\ ${ }^{3}$ Faculty of Engineering, Mahasarakham University, Thailand
}

\begin{abstract}
Localization in soil under high stress level is usually investigated using some indirect measures, e.g., X-ray diffraction method. In the present study, the propagation velocity of shear wave was used to detect localization in sandy soil. Firstly, the general expression to exhibit the stress and density dependencies characteristics under consolidation and triaxial testing conditions of the tested soil was proposed. Adopted the proposed correlation as a reference together with the observed geometry, the shear wave velocity of the localized zone may be assumed. It was found that the density in the localized zone could be much looser than those ever reported in the literature. The void ratio of the localized zone is even larger than the maximum void ratio.
\end{abstract}

Key words: Stress anisotropy, sands, shear modulus, localization

\section{INTRODUCTION}

Localization is one of the most important phenomena determining the performance of laboratory tests. In sample of sandy soil, localization can be visually observed through shear bands. Since occurrence of shear band encounters quite a few intrinsic unknowns, e.g., time of shear band formation, density distribution, thickness and its evolution, a complicated instrumentation, e.g., X-ray computed tomography technique, is usually required to explore its characteristics. Nevertheless, the two most required variables in identification of shear bands are the thickness and density inside the localized zone. In physical models of district normal faulting, shear-bandinduced reduction in sand density due to dilatancy and corresponding reduction in X-ray absorption allows observation of fault development ${ }^{[1]}$. For the evolution of void ratio within shear bands of triaxial sand sample using the X-ray computed tomography technique, the local density inside shear band approaches a limited value of void ratio (critical void ratio). Local void ratio was reported to be much looser than the global measured value ${ }^{[2]}$.

In the present study, the propagation of shear wave through the body of localized sandy sample was adopted to averagely characterize the mechanism of shear band formation in drained triaxial tests ${ }^{[3]}$. The main assumptions of this method are that:
- There exist clear shear bands (rupture surfaces) after peak stress level

- The densities of the intact and localized zones should be distinctly different and

- Since the velocity of shear wave is dependent on both void ratio and stress state, it is therefore necessary to firstly conduct a detail investigation on the stress state and void ratio dependency characteristics of the shear wave velocity. Those stress and void ratio dependency functions are then assumed to be valid locally after failure occurs

When shear bands occur, the propagated shear waves travel through two main bodies of the sample, i.e., the intact and localized parts. The time requires for shear wave to propagate through the sample shall then be the summation of the travel time in the intact part of the sample (thickness of $\mathrm{h}-\Delta \mathrm{h}$ ) and in the localized zone (thickness of $\Delta \mathrm{h}$ ) as schematically shown in Fig. 1. Assuming that the average global travel time is $t_{a v}$ then:

$$
\mathrm{t}_{\mathrm{av}}=\frac{\mathrm{h}}{\left(\mathrm{v}_{\mathrm{s}}\right)_{\mathrm{av}}}=\frac{\mathrm{h}-\Delta \mathrm{h}}{\left(\mathrm{v}_{\mathrm{s}}\right)_{\text {in }}}+\frac{\Delta \mathrm{h}}{\left(\mathrm{v}_{\mathrm{s}}\right)_{\mathrm{lo}}}
$$

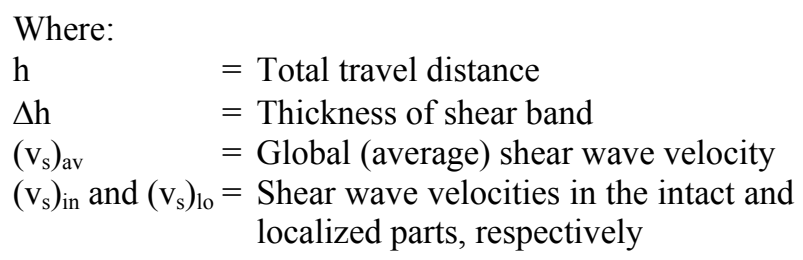



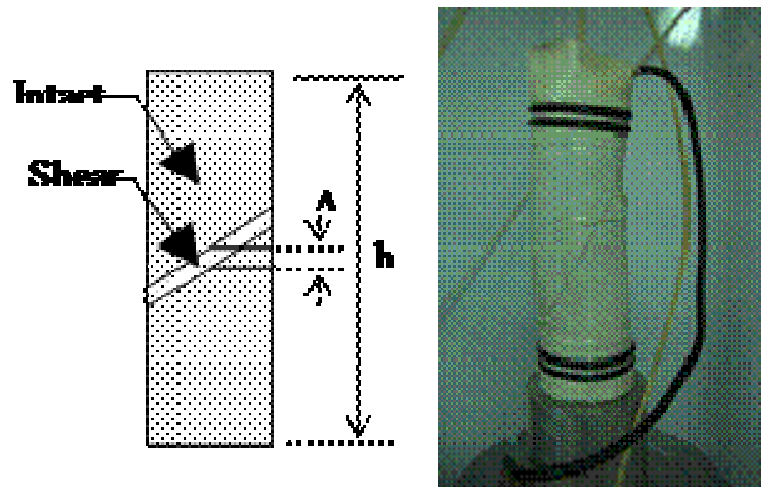

Fig. 1: Test samples after peak deviator stress was attained

There are three variables appearing in Eq. 1, namely, $\Delta \mathrm{h},\left(\mathrm{v}_{\mathrm{s}}\right)_{\text {in }}$ and $\left(\mathrm{v}_{\mathrm{s}}\right)_{10}$. If the thickness of shear band, $\Delta \mathrm{h}$, is small, the void ratio of the intact part may be assumed to be similar to the global void ratio. Therefore, $\left(v_{s}\right)_{\text {in }}$, can be estimated based on the global (average) void ratio. The rest two unknowns, $\Delta \mathrm{h}$ and $\left(\mathrm{v}_{\mathrm{s}}\right)_{\mathrm{lo}}$, are inter-related through the local void ratio inside the shear band. Since the thickness of shear band cannot be determined using the current set-up of the equipment, only the dependent correlation between these two unknowns shall be determined.

\section{MATERIALS AND MATHODS}

Medium coarse sand from a construction site nearby Ping River in Chiang Mai province (northern part of Thailand) was used as tested material. Its grain size distribution, together with some physical properties, is shown in Fig. 2. Cylindrical sample having diameter and height of 70 and $100 \mathrm{~mm}$ was prepared by the air-pluviation method to attain void ratio of around 0.62 (dense sample) and 0.75 (loose sample). After saturation was confirmed, the sample was consolidated to the desired stress condition (isotropic or anisotropic consolidations) and sheared to failure under drained condition. For anisotropically consolidated condition, the sample was consolidated to attain the coefficient of lateral pressure, $\mathrm{k}=\sigma_{3}{ }^{\prime} / \sigma_{1}{ }^{\prime}$, of 0.6 and 0.8 .

A pair of bender elements was installed at the top cap and pedestal of the triaxial cell. Shear wave, generated from the bender element located at the top cap, traveled through the sample to the receiver (bender element) at the pedestal. The shear wave velocity was then determined from sample current height and time of wave arrival. Typical result from a shear wave velocity logging test is shown in Fig. 3. Shear wave velocities

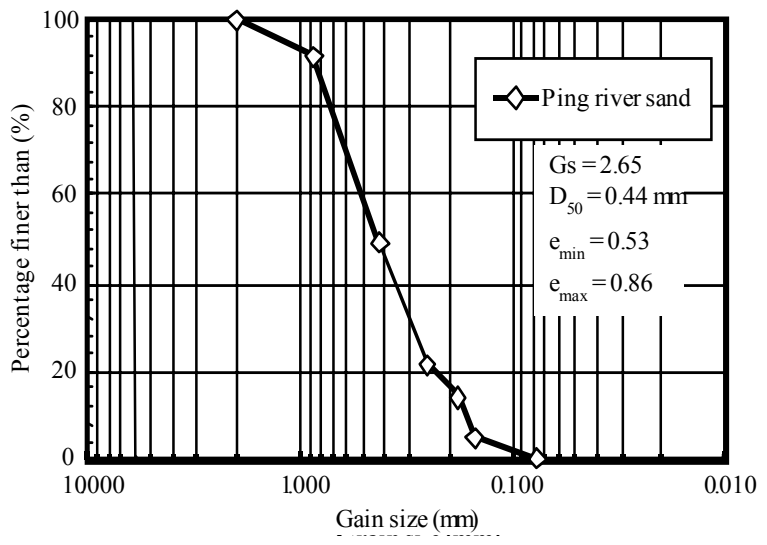

Fig. 2: Grain size distribution of the tested sand

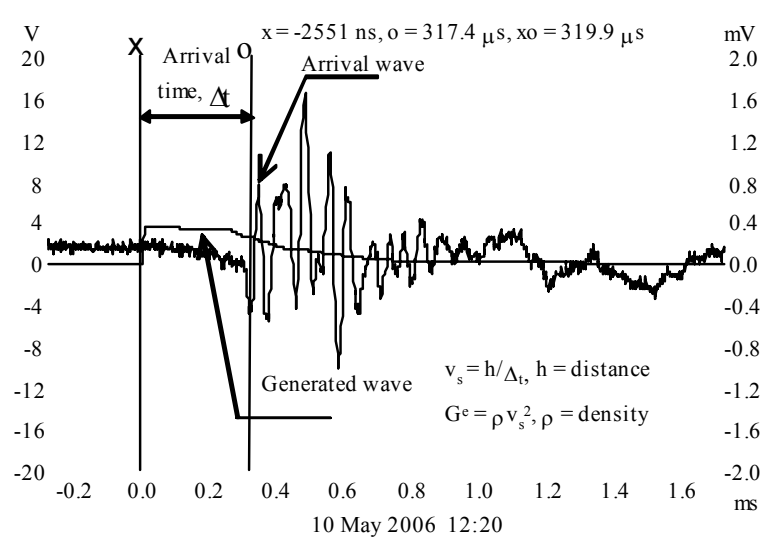

Fig. 3: Typical result from shear wave logging using bender elements

were logged continuously during consolidation and drained shearing. As a consequence, the path of elastic shear modulus (shear wave velocity) against stress and strain states can be investigated under various circumstances (consolidation, pre- and post- failures).

Stress dependency characteristic of the elastic shear modulus: The elastic shear modulus has been well recognized to be dependent on the stress states. Either its dependency on the mean effective stress $\left(p^{\prime}=\left(\sigma_{1}{ }^{\prime}+2 \sigma_{3}{ }^{\prime}\right) / 3\right)$ or the individual stresses acting parallel to the particle motion and wave propagation directions can be found in abundant of literature ${ }^{[1,4-7]}$. The aim of this section is to find the best correlation expressing the influence of stress state and void ratio on the elastic shear modulus of the tested sand. Tests therefore were carried out using both isotropically consolidated $(\mathrm{k}=1.0)$ and anisotropically consolidated $(\mathrm{k}=0.8$ or 0.6$)$ samples. 


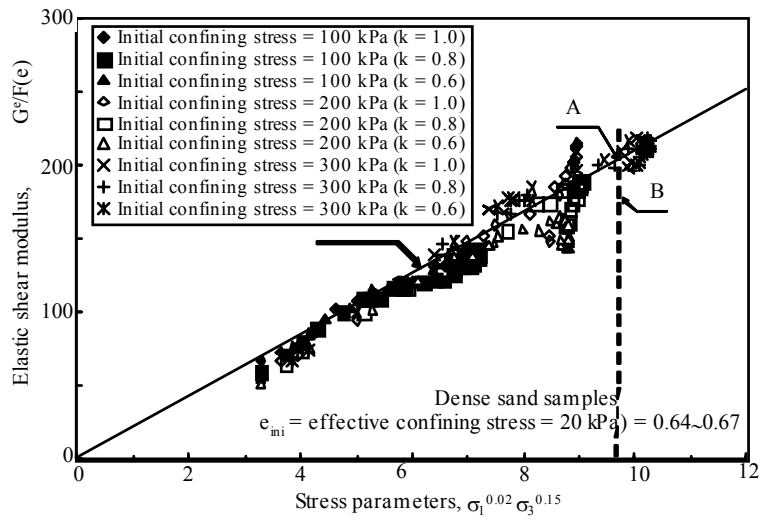

Fig. 4a: Path of elastic shear modulus against stress parameter during drained shearing of dense samples

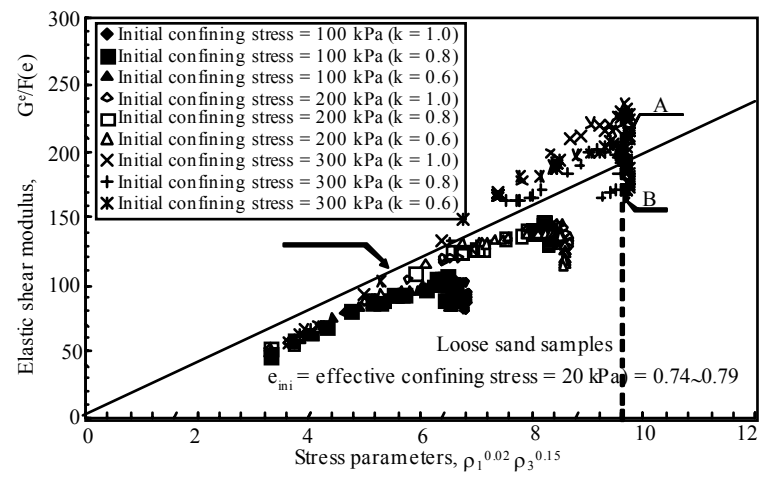

Fig. 4b: Path of elastic shear modulus against stress parameter during drained shearing of loose samples

Figure $4 \mathrm{a}$ and $\mathrm{b}$ show variations of elastic shear moduli $\left(\mathrm{G}^{\mathrm{e}}\right)$ computed from shear wave velocities obtained during consolidation and shearing of loose and dense samples against the stress parameter, $\sigma_{1}{ }^{0.2} \sigma_{3}{ }^{0.15}$. The stress parameter and void ratio function were randomly selected from the literature so that they provided the best fit to the test results. The stress dependency of the elastic shear modulus of the tested sand can be then written as,

$$
\mathrm{G}^{\mathrm{e}}=200\left[\frac{(2.17-\mathrm{e})^{2}}{1+\mathrm{e}}\right]\left[\left(\sigma_{1}{ }^{\prime}\right)^{0.20}\left(\sigma_{3}{ }^{\prime}\right)^{0.15}\right]
$$

Where $\sigma_{1}$ ' and $\sigma_{3}$ ' are in $\mathrm{kPa}$ and $\mathrm{G}^{\mathrm{e}}$ is in $\mathrm{MPa}$. The correlation shown in Eq. 2 is applicable for test results obtained from both loose and dense samples under initially isotopic and anisotropic consolidation

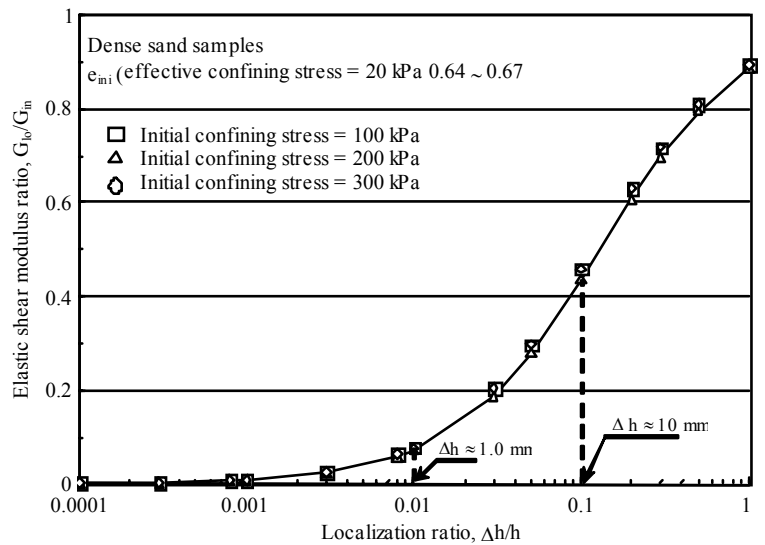

Fig. 5a: Variation of elastic shear modulus against thickness of loosening zone (dense sample)

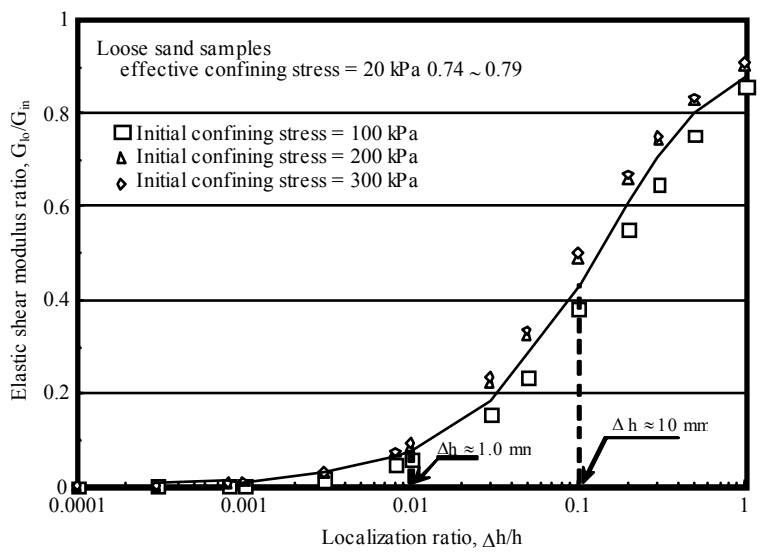

Fig. 5b: Variation of elastic shear modulus against thickness of loosening zone(loose sample)

conditions, prior to failure. After the peak stresses were attained, the above correlation was no further used. The elastic shear modulus rapidly decreases and deviates from the correlation after failure of the sample. This is because of the non-uniform distribution of density due to occurrence of localized zone.

Probable changes of density inside failed sample: The relationships Eq. 1between the thickness of the shear band, $\Delta \mathrm{h}$ and the elastic shear modulus of the sand inside shear band in term of $\mathrm{G}_{\mathrm{lo}} / \mathrm{G}_{\mathrm{in}}$ are shown in Fig. 5a and b. Graphs shown in Fig. 5 were cases derived from the $G_{a v}$ and $G_{i n}$ (designated by points $A$ and B) from Fig. 4. The $\mathrm{G}_{\mathrm{lo}}$ and $\mathrm{G}_{\mathrm{in}}$ represent the elastic shear modulus of the localized and intact zones, respectively. All values of elastic shear moduli are assumed to comply with the correlation expressed in Eq. 2. Since the thickness of the shear band cannot be 
measured by the current equipment, the range of $\Delta \mathrm{h}$ of $1.0-10 \mathrm{~mm}$ (which covers $10-20$ grains thickness) is used. At $\Delta \mathrm{h}$ of 10 grains thickness $(\Delta \mathrm{h}=4.4 \mathrm{~mm})$, the elastic shear modulus of the localized zone must be reduced to about $30 \%$ of the elastic shear modulus of the intact zone. Based on the proposed empirical function Eq. 2, F(e), it is required that the void ratio inside shear band would be very large $\left(\mathrm{e}_{\mathrm{lo}}=1.5-1.6\right)$ which is much greater than its maximum void ratio $\left(\mathrm{e}_{\max }=0.86\right)$. This implies that a sharp broken slip line (void) may be firstly induced under peak stress leveland a few grains of sand in its vicinity may collapse and fill up the void. This results in an ultra loose zone inside the shear band of the failed specimen.

\section{CONCLUSIONS}

It was found that after peak shear strength was attained, the path of the elastic shear modulus, computed from the shear wave velocity, deviated from the proposed empirical line. This change indicates the occurrence of an ultra loose zone inside the localized sample. The void ratio in the localized zone can be much larger than the maximum void ratio of the tested sand.

\section{REFERENCES}

1. Ueta K., Tani K. and Patricia W., 2000. Computerized X-ray tomography analysis of threedimensional fault geometries in basement-induced wrench fault. Eng. Geoogy, 56: 197-210. Doi: 10.1016/S0013-7952(99)00143-X
2. Huang W., Nübel K. and Bauer E., 2002. Polar extension of a hypoplastic model for granular materials with shear localization. Mechanics of Materials, 34: 563-576. Doi: 10.1016/S01676636(02)00163-1

3. Gudehus G. and K. Nubel, 2004. Evolution of shear bands in sand. Geotechnique, 54: 187-201. Doi: 10.1680/geot.54.3.187.36346

4. H. Wolf, D. König, and Th. Triantafyllidis, 2006. The influence of the stress-strain behavior of noncohesive soils on the geometry of shear band systems under extensional strain. Engineering Structures, 28: 1760-1773. Doi: 10.1016/j.engstruct.2005.11.008

5. Tatsuoka F., Iwasaki T. and Fukushima S., 1979. Stress conditions and stress histories affecting shear modulus and damping of sand under cyclic loading. International Journal of Rock Mechanics and Mining Science \& Geomechanics Abstracts, Volume 17, Issue 4, August 1980, Page A63. Doi: 10.1016/0148-9062(80)91149-3

6. Yu P. and Richart F., 1984. Stress ratio effects on shear modulus of dry sands. Int. J. Rock Mechanics Mining Sci. Geomechanics, 21: 129-130. Doi: 10.1016/0148-9062(84)90874-X

7. D. A. Sun, H. Matsuoka, Y. P. Yao and H. Ishii, 2004. An anisotropic hardening elastoplastic model for clays and sands and its application to finite element analysis, Computers and Geotechnics, 31: 37-46. Doi: 10.1016/j.compgeo.2003.11.003 